\title{
Human Care Theory and Influences on the Life Quality Index of Cancer Patients in Household Life
}

\author{
Yali Sun, Ling Gao*, Ying Dong, Ling Gong \\ Beihua University, Jilin, China \\ Email: "bhgaoling@yahoo.com.cn
}

Received June 2013

\begin{abstract}
To investigate the influences of the application of human care theory on the life quality and happiness of cancer patients after they received a community nursing care which was implemented by the human care theory. The quality life and the happiness index of 93 patients with cancer living in the six communities in Jillin were assessed, the assessment of the life quality was based on a life quality scale (SF-36) and that of the happiness index was based on Memorial University of Newfoundland Scale of Happiness (MUNSH). The community nurses cared for these patients by applying the theory of human care and the life quality and the happiness index of the patients were observed after the care. The results showed that there were significant differences in the score of 5 dimensions in the eight dimensions of the life quality between before the care and after the care $(<0.05)$, and there were significant differences in the average sores of the positive emotion, positive experience, negative emotion, negative experience and level of happiness included in the happiness index between before the care and after the care $(<0.05)$, suggesting that the theory of human care can be used for the care of patients with cancer and the application of the theory can effectively improve the life quality and the happiness index of the patients, strengthen their problem-solving abilities and let them have a positive attitude towards their lives.
\end{abstract}

Keywords: Community Nurses; Theory of Human Care; Patients with Cancer; Quality of Life; Happiness Index

\section{Introduction}

With the progress of the times and the rapid development of medical science, cancer has threaten to human health and put tremendous psychological burden on the patients and their families, causing a significant decrease in the life quality and the happiness index of the timorous patients [1,2]. Because of the advance in medical technology, the survival period of patients with cancer has been significantly prolonged. In the present time, the quality of life has been more and more concerned by the whole society. In this study, the change in the quality of life of tumorous patients was observed and studied after the implementation of humane care which was given to the tumorous patients [3].

\section{Materials and Methods}

\subsection{General Information}

93 Cases of patients with malignant tumor were selected. They were made a definite diagnosis before March 2011 and their sick years were $1 \pm 0.6$. After the combined treatment in a hospital, they live their home lives, they

${ }^{*}$ Corresponding author. can take care of themselves, their vital signs were stable, there was no communication barrier in language for them, all of them had received an education at least in a junior high school, and most of them were voluntary to participate in the community health educational activities. The average age was $(57 \pm 7.2)$ years. There were 59 male and 47 female patients including 15 cases of pancreatic cancer, 18 cases of breast cancer, 16 cases of cervical cancer, 6 cases of rectal cancer, 22 cases of gastric cancer, 11 cases of lung cancer and 5 cases of esophageal cancer. The selected requirement for the community nurses who would implement the human care included that they had to have at least more than 10 years of clinical experience, and they should have gained some understanding in the theoretical connotation of human care, the knowledge of human care, the skill for communication with patients, and knowing about the concept of humane care and the status of human care. 12 nurses who met the selected requirement were appointed to carry out the human care for the patients in their own communities.

\subsection{Methods}

The 93 patients selected were assessed on the existing quality of life. Based on the quality life scale (SF-36) [4], 
the assessment was conducted according to 8 dimensions and 35 items. The eight dimensions included the physiological function (10 items), physical performance (4 items), general health (5 items), body pain (2 items), vitality (4 items), social communication function (2 items), emotional functions (3 items) and mental health (5 items). The score of the physiological function was $10 \sim 30$ points, the score of body pain was $2 \sim 11$ points, and all the other items were $1 \sim 5$ points. The score for each item was positively proportional to the quality of life.

The happiness indexes of 93 Patients selected were assessed and assessment was conducted based on Memorial University of Newfoundland scale of Happiness (MUNSH) [5]. MUNSH contains 24 items. Among the 24 items, 10 items are considered to reflect the positive and negative emotions, 5 items the positive emotion (PA), 5 items the negative emotion (NA), 14 items positive and negative experiences, 7 items the positive experience (PE), and 7 items the negative experience (NE). The total happiness index: PA-NA + PE-NE. The determination of score was based on the following rule: that the answer to each item was "yes" was recorded 2 points, that the answer to each item was "I don't know" was recorded 1 point, and that the answer to each item was "No" was recorded 0 point; that the answer to item 19 was "the residence where he or she is living now" was recorded points and "any other residence" was recorded 0 point; that the answer to item 23 was "satisfactory" was recorded 2 points and "unsatisfying” was recorded 0 point. The range of the total average point was from -24 to +24 points. In order to be easy to calculate the score, 24 , as the constant, was added, and the score range was from 0 to 48; the higher the score the higher the happiness index.

The community nurses implemented their human care by applying the 10 factors for the human care described in the theory of human care set up by Dr. Watson J. The patients were made three appointments a week, the time for each appointment was not less than 60 minutes, the care was implemented in a way of a small course or separately aiming at the particular case for different patients and the appointment could not be missed. During the care, the human care were particularly emphasized, science and humanities knowledge was integrated and used to communicate with the patients, and the human care was completed based on 10 factors proposed in the theory of human care. 10 factors for human included forming a value system of the human altruism; inculcating a trust and hope; developing a sensitivity of themselves and others; building up a relationship in helping, trusting and caring; encouraging and accepting the expression of positive emotions and negative emotions from the clients; applying scientific methods to solve problems in the decision-making system; providing a psychological, social and spiritual environment to sup- port, protect and correct them; helping meet individual needs; allowing the presence of existentialism, phenomenology and spiritual power. The community nurses should follow the nature of human care to give the patients with cancer a psychological support and cultural care, answer any questions for them or explain the related successful stories and so on.

After the community human care was implemented over 3 months, the life quality and the happiness index of the 93 patients was assessed again based on the life quality scale (SF-36) and MUNSH.

\subsection{Statistical Method}

SPSS soft ware was used to analyze the survey data in this study. The least significant difference (LSD) and SNK variance analysis methods were applied to compare a pair of data obtained before the care and after the care. $\mathrm{P}<0.05$ meant a significant difference.

\section{Results}

The results showed that both patients' life quality and happiness index after the human care were different from those before the human care, there were significant differences in 5 dimensions which could reflect the life quality of the patients, such as physical performance, life vitality, social communication ability, emotional function and spiritual health $(<0.05)$, which were shown in Table $\mathbf{1}$ in detail; average scores of the positive emotion and positive experience were significantly increased after the care $(<0.05)$, those of the negative emotion and the negative experience were significantly decreased $(<0.05)$, and the difference in the total average sore of the happiness index was significant before and after the application of the human care theory $(<0.05)$, which were shown in Table 2 in detail. The assessment on the life quality and

Table 1. Comparison in SF-36 score between before and after the implementation of the human care theory (points) $\bar{X} \pm s$.

\begin{tabular}{lccc}
\hline Dimensions & $\begin{array}{c}\text { Average sore at the } \\
\text { first assess }\end{array}$ & $\begin{array}{c}\text { Average sore after } \\
\text { the human care }\end{array}$ & p values \\
\hline $\begin{array}{l}\text { Physiological } \\
\text { function }\end{array}$ & $13.21 \pm 6.12$ & $13.91 \pm 4.62$ & $>0.05$ \\
$\begin{array}{l}\text { Phusical } \\
\text { performance }\end{array}$ & $6.06 \pm 2.22$ & $7.81 \pm 1.82$ & $<0.05$ \\
$\begin{array}{l}\text { General health } \\
\text { Physical pain }\end{array}$ & $10.03 \pm 3.57$ & $10.52 \pm 4.89$ & $>0.05$ \\
$\begin{array}{l}\text { Life vitality } \\
\text { Social contact }\end{array}$ & $8.25 \pm 3.09$ & $6.94 \pm 4.99$ & $>0.05$ \\
function & $6.42 \pm 5.83$ & $8.97 \pm 2.72$ & $<0.05$ \\
$\begin{array}{l}\text { Emotional } \\
\text { functions }\end{array}$ & $4.14 \pm 3.36$ & $5.76 \pm 1.79$ & $<0.05$ \\
Spiritual health & $8.63 \pm 4.18$ & $13.11 \pm 2.79$ & $<0.05$ \\
\hline
\end{tabular}


Table 2. Comparison in happiness between before and after the implementation of the human care theory (points) $\bar{X} \pm s$.

\begin{tabular}{lccc}
\hline Items & $\begin{array}{c}\text { Before the } \\
\text { implementation }\end{array}$ & $\begin{array}{c}\text { Before the } \\
\text { implementation }\end{array}$ & p values \\
\hline Positive emotion & $2.75 \pm 2.8$ & $4.82 \pm 2.5$ & $<0.05$ \\
Negative emotion & $7.26 \pm 2.4$ & $4.31 \pm 3.7$ & $<0.05$ \\
Positive experience & $4.13 \pm 2.6$ & $6.82 \pm 3.3$ & $<0.05$ \\
Negative experience & $11.03 \pm 2.7$ & $9.25 \pm 2.6$ & $<0.05$ \\
Total happiness score & $12.59 \pm 2.8$ & $22.08 \pm 3.7$ & $<0.05$ \\
\hline
\end{tabular}

happiness index of patients with cancer based on SF-36 and MUNSH demonstrated that the application of human care theory could improve the life quality and happiness index of patients with cancer.

\section{Discussion}

It is well known that the daily life of cancer patients is limited, their life skills are decreased significantly, their social activities are reduced, they are always lack of interpersonal communications and emotional support, and often show a negative attitude to the present life, and moreover, the disease can cause the decrease in their body resistances to directly affect the life quality of them and the happiness index. Community nurses applied the human care theory to give a respect to the personality of the patients and look after them with a personalized care, which can give the patients an individualized treatment. The care emphasized on patient-centered and the service for the clients with love, patience and in an all-around way, which could improve the life quality of patients with cancer significantly. The results in this study showed that compared with those before the implementation, there were significant differences in the factors which can be used to assess the life quality of patients with cancer, such as the physiological performance, social function, emotional function, mental health and vitality after the implementation of the human care theory $(p<0.05)$, there was no significant difference in physiological function, general health and body pain ( $p>0.05$ ), and the happiness index of the patients was significantly elevated after the implementation of the human care theory. Therefore, the theory and the method of human care should be applied universally, and all nurses should understand the meaning of human care theory and the knowledge of human care in their future work. It is believed that the application of the human care theory will be a new development in nursing.

\section{REFERENCES}

[1] E. Frick and M. Panzer, "Depression and Quality of Life of Cancer Patients Andergoing Radiation Therapy. A Cross-Sectional Study in Community Hospital out Patient Centre,” European Journal of Cancer, Vol. 16, No. 2, 2007, pp. 130-136. http://dx.doi.org/10.1111/j.1365-2354.2006.00720.x

[2] M. Golant, T. Aiman, C. Martin, et al., "Managing Cancer Side Effects to Improve Quality of Life A Cancer Psychoeducation Program,” Cancer Nursing, Vol. 26, No. 1, 2003, pp. 36-44. http://dx.doi.org/10.1097/00002820-200302000-00005

[3] J. Watson, "Nursing: Human Science and Human Care," National League for Nursing, New York, 1985, pp. 1-3

[4] L. Li, H. M. Wang and Y. Shen, "Development and Psychometric Tests of a Chinese Version of the SF-36 Health Survey Scales," Chinese Journal of Preventive Medicine, Vol. 36, No. 2, 2002, pp. 109-113.

[5] X. D. Wang, X. L. Wang and H. Ma, "Rating Scales for Mental Health (Supplementary Edition)," Chinese Mental Health Journal, Beijing, 1993, p. 31. 